\title{
IDENTIDADE E MEMÓRIA: UMA PERSPECTIVA ELIASIANA DA CONSTRUÇÃO DE NACIONALIDADES
}

\author{
Marcos Aurelio Dornelas D1, Tulane Silva de Souza Pedrosa iD2 \\ Catarina da Silva Souza iD3 e Charles Gomes Martins iD4
}

\section{Resumo}

Quando a globalização tecnológica e política avançava pelo mundo e o neoliberalismo parecia ter se tornado hegemônico no planeta, o pósnacionalismo tornou-se uma realidade quase palpável. Nessa perspectiva, os Estados-nações estariam com seus dias contados. O século XXI por outro lado, tem nos mostrado que o nacionalismo em suas vertentes políticas e econômicas está mais vivo do que nunca como forma de integração e de legitimação de identidades e memórias. A fim de compreender este momento histórico, debatemos com Norbert Elias a relação entre identidade e memória e sua implicação na formação das nacionalidades. Para tanto, faremos uma revisão dos pressupostos teóricos eliasianos com o objetivo de verificar o papel da nacionalidade na construção identitária na modernidade a partir da perspectiva da sociologia dos processos, analisando as possibilidades de um pósnacionalismo num futuro que agora parece cada vez mais distante. Buscamos expor em nossa argumentação que Elias demonstra inequivocamente que, em curto e médio prazo, os nacionalismos devem preservar sua força integradora. De maneira complementar, evidencia também que no processo de longa duração da formação de Estados, as nações são apenas uma das etapas possíveis de integração e não a etapa final. O pós-nacionalismo, neste sentido, é ao menos uma possibilidade teórica.

Palavras-chave: Nacionalismo; identidade; memórias.

\section{IDENTITY AND MEMORY: AN ELIASIAN PERSPECTIVE ON NATIONALITY BUILDING}

\begin{abstract}
When technological and political globalization advanced across the world and neoliberalism seemed to have become hegemonic on the planet, postnationalism became an almost palpable reality. In this perspective, nation-states would have their days numbered. The 21st century, on the other hand, has

\footnotetext{
${ }^{1}$ Doutor em Sociologia, docente do Departamento de Sociologia da Universidade Federal de Pernambuco (UFPE).

${ }^{2}$ Doutoranda em Educação pela Universidade Federal de Pernambuco (UFPE) e mestre em Educação pela UFPE.

${ }^{3}$ Doutoranda em Educação pela Universidade Federal de Pernambuco (UFPE) e mestre em Educação pela UFPE. Docente da Universidade Federal do Agreste de Pernambuco (UFAPE).

${ }^{4}$ Doutorando em Educação pela Universidade Federal de Pernambuco (UFPE) e mestre em Educação pela UFPE. 
shown us that nationalism in its political and economic aspects is more alive than ever as a form of integration and legitimization of identities and memories. In order to understand this historical moment, we debated with Norbert Elias the relationship between identity and memory and their implication in the formation of nationalities. Therefore, we will review the theoretical assumptions of Elias in order to verify the role of nationality in the construction of identity in modernity from the perspective of the sociology of processes, analyzing the possibilities of a post-nationalism in a future that now seems increasingly distant. We seek to show in our argument that Elias unequivocally demonstrates that, in the short and medium term, nationalisms must preserve their integrative force. In a complementary way, it also shows that in the long-term process of the formation of States, nations are only one of the possible stages of integration and not the final stage. Post-nationalism, in this sense, is at least a theoretical possibility.

Keywords: Nationalism; identity; memories.

\section{Apresentação}

O foco deste trabalho é tratar da relação entre identidade e memória e sua implicação na formação da nacionalidade a partir dos escritos de Norbert Elias. Desde já é importante frisar a relevância da temática no contexto atual. Há bem pouco tempo falava-se em cosmopolitanismo (BECK, 2000, 2002), pósnacionalismo (HABERMAS, 2000) (BECK 2006), fim da história (FUKUYAMA, 1992) ou outros termos correlatos como um fato sociológico acabado e o nacionalismo como uma realidade em vias de superação.

A noção de pós-nacionalismo havia entrado na ordem do dia com o fortalecimento da agenda neoliberal, com a internacionalização das finanças e da indústria da comunicação. Parecia emergir junto uma ordem política global correlata ao avanço econômico e das comunicações. Particularmente no contexto europeu a articulação política figurava intrinsecamente vinculada à convergência monetária, econômica, militar e mesmo judicial.

Entretanto, este processo tem sofrido revezes nos últimos anos. No campo político-econômico, basta lembrar do 'brexit' ${ }^{5}$ ou das eleições nos EUA, em 2016, quando Donald Trump foi eleito com slogans nacionalistas, tais como "A América em primeiro lugar" e "Torne a América grande de novo". Ou mesmo aqui, no Brasil, o uso do mesmo tipo de discurso pelo atual presidente Jair Bolsonaro. Seu Slogan da campanha, vale lembrar era "Brasil acima de Tudo, Deus acima de Todos".

Deste modo, o pós-nacionalismo tão alardeado deve ser posto em suspeição. Nos parece ser ainda importante tratarmos do nacionalismo e deu suas implicações na contemporaneidade. Para melhor compreendermos o lugar no nacionalismo no mundo atual, trazido novamente ao centro do debate acadêmico, apresentamos uma revisão de seus pressupostos teóricos e 
procuramos entender o seu papel na construção identitária do homem moderno. Ademais, analisaremos as possibilidades concretas de um pós-nacionalismo na perspectiva da sociologia dos processos.

Em termos da organização do texto, inicialmente faremos uma contextualização das obras as quais Elias destacadamente debateu a questão das memórias e das identidades atreladas ao nacionalismo. Em seguida partimos para o diálogo com Norbert Elias por meio de temas que nos levarão a uma aproximação progressiva com a questão das nacionalidades. Na seção Habitus, códigos de conduta e identidade, tratamos dos processos de humanização e da construção das identidades coletivas e individuais. Na segunda parte, Identidade, memória e nacionalismo, analisamos o papel da construção de um passado glorificado na formação do nacionalismo. Na seção seguinte, Autonomia relativa, Comunicação e conhecimento, debatemos a forma como o conhecimento, em nível simbólico atua nas nacionalidades. Em Conflitos, nação e nacionalismo, pretendemos entender o lugar dos conflitos entre nações e da ideologia no mesmo processo. Já no tópico É possível uma integração para além da nação? Apresentamos e debatemos o que à primeira vista parecem ser duas perspectivas na obra eliasiana em relação a construção das nacionalidades. Por fim, apresentamos nossas considerações finais.

Consideramos que quatro publicações de Elias são fundamentais para alcançarmos os objetivos aqui propostos, são elas: 'Os alemães' 'A condição Humana', 'A sociedade dos indivíduos' e 'Teoria Simbólica'. Por reconhecer a centralidade dessas obras em nosso debate, vamos contextualizar brevemente cada uma delas.

A Condição Humana (ELIAS, 1991) foi escrito no ano de 1985, por ocasião do aniversário de quarenta anos do fim da Segunda Guerra Mundial. A reflexão central do texto gira em torno da especificidade humana em relação aos conflitos bélicos. Nos interessa particularmente a relação demonstrada por Elias entre as guerras movidas pelas nações e a construção das identidades nacionais e memórias individuais e coletivas. Segundo Elias (1991) a guerra é uma condição de vida humana, estando assim, enraizada nas suas instituições sociais.

A obra, A Sociedade dos Indivíduos, publicada em 1987, é composta de três ensaios: o primeiro escrito em 1939, o segundo realizado entre 1940 e 1950 e o terceiro ensaio produzido entre 1986 e 1987. A discussão central do livro é, evidentemente, o problema da relação indivíduo e sociedade. É desta obra a famosa metáfora da bola de bilhar, com a qual Elias compara a constituição de uma sociedade de indivíduos: " elas se chocam e rolam em direções diferentes. Mas a interação entre as pessoas e os 'fenômenos reticulares' que elas produzem são essencialmente diferentes das interações puramente somatórias das substâncias físicas" (ELIAS, 1994, p.29).

Ainda no prefácio de Os alemães, Dunning e Mennell colocam que este fora o último livro de Elias publicado com ele ainda vivo e que contou com sua aprovação direta. O livro, no original alemão, veio a público exatamente 50 anos após a publicação de O processo civilizador. Tanto na obra dos anos 1930, quanto em Os alemães, Elias busca demonstrar a estreita ligação entre a 
formação dos Estados nacionais e os processos de desenvolvimento microssociais, notadamente na constituição dos habitus dos indivíduos.

O livro Teoria Simbólica foi produzido por Elias em 1988, quando o autor já contava 91 anos de idade. O texto foi publicado somente em 1991, um ano depois do falecimento do sociólogo. E mesmo com a introdução inacabada, conjectura sem espaço para dúvidas uma série de ensinamentos acerca da interação entre social e biológico, forte característica da multidisciplinaridade do sociólogo. A versão em português de Portugal foi publicada em 1994, e é de fácil compreensão, apesar de pouco utilizado no que tange aos estudos da comunidade eliasiana quando comparado aos estudos da juventude de Elias.

\section{Habitus, códigos de conduta e identidade}

Por meio do conceito de habitus, Elias busca descrever e compreender os fatores relacionados a humanização do humano, ou dito de outra forma, sobre a construção de identidades coletivas e individuais. O autor se utiliza do conceito para pensar de modo dinâmico - entre rupturas e continuidades - os processos de construção dos saberes sociais incorporados nos indivíduos de um determinado grupo ou sociedade. De modo que "o habitus nacional de um povo não é biologicamente fixado de uma vez por todas; antes está intimamente vinculado ao processo particular de formação do Estado a que foi submetido" (ELIAS, 1997, p. 16).

Portanto, para se compreender as mudanças nos padrões de comportamento dos indivíduos - nos seus habitus - é preciso reconhecer e examinar a mudanças dos processos de civilização, bem como das figurações dos modelos de civilização. Isto porque os indivíduos formam entre si unidades de subsistência nos quais "eles são herdeiros não só de uma linguagem específica, mas também de um modelo específico de civilização e, portanto, de formas específicas de autorregulação" (ELIAS, 2006, p. 23).

Duas mudanças nos processos de civilização são importantes para nossa discussão, uma delas está relacionada a economia, principalmente aquelas advindas da industrialização. Outra mudança importante diz respeito a emancipação de grupos antes marginalizados social e economicamente. Estes movimentos de emancipação Elias intitula de processos de democratização funcional. Nesses processos, diminui-se também 0 hiato de poder entre governantes e governados e entre as próprias instituições do estado e a população em geral. Um dos efeitos empíricos mais evidentes desta mudança é a diminuição da formalidade no trato entre esses grupos, evidenciando a transformação nos códigos de comportamento.

O código convencional que rege o comportamento entre grupos, que estava afinado em função de uma ordem hierárquica mais rígida, deixou de corresponder às relações reais de seus membros. Só será possível o surgimento gradual de um novo código de comportamento através de muitas experiências. Levando tudo em conta, este é um século de crescente incerteza de status. Com uma 
transformação das relações de poder como tal, o problema de identidade social também se tornou muito mais explícito do que numa sociedade onde o ritmo de mudança não é tão acelerado. Com a crescente insegurança de status e uma também crescente busca de identidade, as preocupações aumentam. (ELIAS, 1997, p. 37).

Aos indivíduos que fazem parte das configurações cujo movimento descrevemos, as mudanças ora parecem abruptas, ora lentas demais. Dai a necessidade de o pesquisador atentar-se ao que Elias nos lembra recorrentemente: analisar as mudanças sociais enquanto processos de longa duração. (1992, 1993, 1994, 2001) Procedendo de outro modo, corre-se o risco de naturalizar aspectos sociais, quando a única certeza que temos no que tange as relações humanas é que nada é natural, tudo é socialmente construído, inclusive as memórias, que fundam as identidades.

Convêm lembrar, entretanto, que esse caráter de construção não implica numa percepção consciente dos indivíduos de que estão construindo memórias coletivas. Por exemplo, os códigos de moralidade sistematizados; em tese tais códigos não mudam de forma linear em todas as esferas sociais. Quando pensadores burgueses naturalizam valores que constituirão o pano de fundo da construção de classe - que será depois elemento para a construção das nacionalidades -, na maioria dos casos eles creem, de fato, que esses valores são naturais e universais (ELIAS, 1997).

É certo que algumas condutas gestadas em determinados grupos ou classes sociais escapam às suas fronteiras, e tornam-se características por vezes de uma nação inteira. Entretanto, quase sempre as condutas diferenciadas servem inicialmente para identificar e notabilizar membros de determinados grupos. É característica comum de grupos sociais com relações consolidadas a existência de códigos de comportamento tácitos ou velados que acabam por tornar-se uma segunda natureza na personalidade de cada um de seus membros.

O habitus resultante dessa profunda consolidação se observa nas atitudes e modos de expressão de ideias e de algum modo se constitui na recompensa individual pela lealdade ao grupo tornando-se, desde modo, um fator de distinção social. Dito de outra forma, esses códigos são obviamente reconhecíveis àqueles que compartilham o mesmo código de comportamento, cumprindo uma função de reconhecimento entre pares. Um exemplo esclarecedor dessa característica do habitus de grupo é a forma como Elias caracteriza os Gentlemen, na sociedade inglesa moderna

Eles se distinguiam de integrantes de outros grupos sociais não apenas por sua influência real ou simulada e pelo poder derivado de um contato mais próximo com aqueles que governavam o país, mas também por suas maneiras e ambições, suas virtudes e vícios, e todo o seu modo de vida. (ELIAS, 2006, p.99) 
Assim, a mais destacada função dos habitus diferenciados é demonstrar aos não-membros como aquele grupo age e se diferencia dos outros. Além disso, e de forma complementar, as regras de conduta utilizadas para identificar e distinguir um indivíduo na sociedade são as mesmas que, ao não serem cumpridas segundo a expectativa do grupo de filiação, geram punições que variam deste a estigmatização dentro do grupo até a completa exclusão.

E o temor dessas sanções é tanto mais eficaz nesse caso, uma vez que ameaça destruir não apenas a carreira mas também a própria identidade da pessoa em questão. Pois se uma pessoa cujo orgulho pessoal, amor-próprio e senso de superioridade são legitimados através da pertença à classe alta vem a perder sua posição como membro da elite e do mais poderoso estrato de sua sociedade por violar seu código, isso envolve uma perda de identidade e de autoestima que é frequentemente irreparável; é difícil recuperá-las e refazer-se de tal perda. (ELIAS, 1997, p. 110).

Conforme Elias, o que foi dito acerca de grupos ou classes sociais é válido também para grupamentos maiores, como as nações. "existem conexões análogas entre o destino e as experiências a longo prazo de um povo e seu habitus social em qualquer época subsequente" (1997, p. 30). Deste modo, a questão de pesquisa a se enfrentar é 'como' as venturas e desventuras de uma nação ficam sedimentados nos habitus das pessoas. Esse, aliás, é o tema central do primeiro volume de O Processo Civilizador (ELIAS, 1994).

Há relação entre a formação dos estados-nacionais e a constituição dos habitus dos indivíduos, na medida em que os indivíduos possuem diversas camadas em sua estrutura de personalidade. É numa delas, a camada-nós, que são inscritas - por processos educativos os mais diversos - as memórias coletivas que resultarão nos códigos de comportamento típicos do grupamento social o qual o indivíduo faz parte. "Os destinos de uma nação cristalizam-se em instituições que têm a responsabilidade de assegurar que as pessoas mais diferentes de uma sociedade adquiram as mesmas características, possuam o mesmo habitus nacional." (ELIAS, 1997, p. 29).

\section{Identidade, memória e nacionalismo}

No processo de socialização, os indivíduos vivenciam uma série de fatos que irão nortear a formação de sua identidade. Para compreender estas variantes que perpassam o ser humano é preciso superar a visão simplista de que há um abismo intransponível entre a sociedade e os indivíduos. Para Elias não precisamos definir se a sociedade e os indivíduos são meios ou fins em si mesmos. Em sua visão precisamos romper com esta dicotomia e entender que a vida social é repleta de contradições e tensões (ELIAS, 1994b).

Neste contexto de diversas tensões e contradições o indivíduo cresce imerso numa teia de relações humanas. Ao nascer, os indivíduos já encontram funções sociais definidas as quais são transmitidas inicialmente pela família; sua 
margem de manobra social é, portanto, inicialmente bastante limitada. Para Elias (1994b, p. 30) "a historicidade de cada indivíduo, o fenômeno do crescimento até a idade adulta, é a chave para a compreensão do que é a sociedade."

Quando refletimos sobre o desenvolvimento da identidade no sujeito precisamos compreender que este indivíduo se estabelece enquanto humano quando se relaciona com outras pessoas. Esta maleabilidade destas funções relacionais é vista por Elias como uma moldagem para a autorregulação.

[...] toda sociedade humana consiste em indivíduos distintos e todo indivíduo humano só se humaniza ao aprender a agir, falar e sentir no convívio com outros. A sociedade sem os indivíduos ou o indivíduo sem a sociedade é um absurdo. (ELIAS, 1994b, p. 67).

Quando pensamos em identidade estamos nos referindo a algo sedimentado em valores e crenças e que serve de referência a ações. É assim de tal modo, que por vezes, na prática social cotidiana, a tendência é tratar a identidade - seja individual ou coletiva - como algo estático que após certa consolidação, não muda com o decorrer do tempo. Elias, por outro lado, nos fala da construção das identidades, ou do nós-imagem, como na maioria das vezes se refere, como um processo dinâmico, não totalmente orientado por um indivíduo singular, grupo ou classe (ELIAS, 1997).

De modo geral na Europa, até o século XVIII, as elites intelectuais de classe média cultivavam a crença em princípios morais baseados na noção de progresso da humanidade. Com a gradativa ascensão dessas classes médias aos postos de liderança política a crença num progresso geral foi sendo deixada de lado em favor de uma idealização das nações. "Uma vez elevadas à posição de classes dominantes, suas seções de liderança e suas elites intelectuais, à semelhança de outros grupos dirigentes, trocaram o futuro pelo passado a fim de basear neste sua imagem ideal delas próprias" (ELIAS, 1997, p. 129).

A partir exatamente deste 'olhar para trás', se começa o processo de construção de um passado glorificado, de uma memória reificada. No uso da memória coletiva para fins políticos, as palavras de ordem deixam de ser futuro e progresso para ser herança e tradição. Nesse tipo de construção, cria-se um nós-imagem que aponta para um nós-ideal ambos pautados no passado.

$\mathrm{Na}$ formação dos Estados-nações europeus, e americanos, claro, com suas especificidades, os grupos aristocráticos dominantes basearam seus valores na ancestralidade familiar. Seus sucessores como classe dominante, as classes médias industriais, e mesmo posteriormente as classes trabalhadoras industriais, fundaram seu orgulho de classe na ancestralidade nacional ou mesmo em realizações e valores nacionais; em comum o caráter pretensamente imutável dos valores.

Uma diferença importante entre a perspectiva aristocrática e a dos grupos industriais nas suas construções de memórias diz respeito a pretensão 
universalista do segundo grupo. Enquanto os valores, crenças e mesmo as restrições autoimpostas em termos de honra e civilidade dos aristocratas pertenciam somente a estes e era fator de distinção social cabendo aos plebeus pouco mais que uma lealdade imposta, no caso dos grupos industriais da classe média interessava o espraiamento de seus valores fundados na noção de moralidade e virtude (ELIAS, 1997).

Com as classes médias, menos dependentes das regulações feitas pelos pares, entretanto, mais dependentes das regulações autoimpostas - as virtudes, as coerções internas alcançaram patamares maiores que o observado entre os aristocratas. Alçaram patamares maiores não apenas em termos qualitativos: mais autocoerção num único indivíduo, mas também, e mesmo principalmente, no sentido quantitativo, já que os valores e as memórias da classe média serão universalizados para todos os indivíduos, um processo de construção de memórias coletivas operacionalizada, entre outros mecanismos, pelo sistema escolar oficial de cada nação (ELIAS, 1997).

A noção de identidade coletiva implicada na perspectiva nacionalista é uma característica do mundo moderno, mais especificamente, da sociedade de classes. A sociedade estratificada senhorial que foi aos poucos ou abruptamente solapada na Europa não tinha seus equivalentes de sentimentos-nós, como será comum observar nas nações do século XIX e XX. As lealdades que geravam engajamento identitário eram outras, pois as estruturas sociais eram outras. "Somente em sociedades-classes, não em sociedades-estados, é que os sentimentos de identidade das elites dominantes e, com o passar do tempo, também os de estratos mais amplos, adquiriram o cunho específico de sentimentos nacionais" ( ELIAS, 1997, p. 137).

A lealdade antes personalizada na figura de um monarca, nas sociedades de classes será cada vez mais ligada a uma imagem idealizada de nação. Assim, toma posto de valor público supremo, no nível mesmo das crenças, solapando, a um só tempo valores personalísticos e eventualmente valores humanistas e moralistas que gravitassem em torno de reis ou de classes em ascensão.

A identificação entre os concidadãos tornou-se mais forte, mesmo em detrimento da identificação que seria possível entre pessoas de mesma classe em diferentes nações. Ainda que a princípio pareça contraditório, ao que tudo indica é a estruturação das sociedades de classes que afasta os indivíduos de classes sociais equivalentes mas de diferentes estados-nações. "Essa mudança no padrão de "sentimentos-de-nós-e-eles", de identificação e exclusão, foi uma das principais condições do desenvolvimento de sentimentos, valores e crenças nacionalistas" (ELIAS, 1997, p. 137).

Deste modo, as lealdades antes pessoa-a-pessoa, passam a ser preponderantemente lealdades simbólicas - bandeiras, hinos, heróis etc. Uma vez que a coletividade soberana identificada como nação opera no nível simbólico, a relação que se concretiza com cada um dos indivíduos da sociedade é bem mais complexa e o vínculo emocional com os símbolos nacionais precisam ser reforçados constantemente para que o indivíduo nunca duvide de sua conexão pessoal com a nação nem das qualidades particulares que esta carrega. 
Não que a simbologia das monarquias não implicasse esforço para sua manutenção, mas, no caso das nacionalidades, o indivíduo se sente parte intrínseca da nação o que não acontecia com os reis, estes se colocavam acima das pessoas e das coletividades. Conforme Elias (1997, p. 143),

[...] o amor de um indivíduo pela sua nação nunca é apenas amor por pessoas ou grupos de pessoas a que se refere como "eles"; também é sempre o amor de uma coletividade a que o indivíduo se refere como "nós". Seja que mais possa ser, é também uma forma de amor-próprio.

Elias reconhece a importância da aproximação da noção de auto-imagem dos indivíduos e nós-imagem da nação. Argumenta, entretanto, que é preciso superar os limites do conceito de 'identificação' que faz parecer que indivíduo e nação sejam entidades diferentes e separadas no tempo-espaço. Em sua perspectiva, o indivíduo carrega em si o 'eu-imagem' e o 'nós-imagem' e um não pode ser analisado sem ter em conta o outro. Para tratarmos de um fato histórico concreto, podemos lembrar do pós-segunda guerra na Alemanha, quando o fato de muitos alemães não terem participado dos atos do nazismo (seja por uma questão de geração, seja por não ter participado diretamente, mesmo sendo contemporâneo), não deixam de carregar consigo este momento da história alemã, ou seja, a reputação do grupo que pertencemos também "interfere" ou "participa" da nossa construção identitária individual. Para Elias (1985) isto se dá pois, "os homens transportam consigo, no seu habitus pessoal, particularidades dos habitus do seu grupo." (Idem, p. 52).

Em termos analíticos, a partir de um par caro a Elias, não se pode compreender o processo de sociogênese - neste caso a nacionalização do ethos nacionalista nas sociedades estados dos séculos XIX e XX - e portanto, as especificidades das estruturas sociais, sem também compreender os processos psicogenéticos específicos da constituição da estrutura de personalidade dos indivíduos nestas sociedades. Elias se refere, por exemplo aos significados e usos específicos de certas palavras com forte implicação emocional para determinadas nações muitas vezes transmitidas de geração em geração que tem um papel de continuidade e de segurança grupal e por vezes relacionadas ao que se convencionou chamar de caráter nacional (ELIAS, 1994a).

Ao lado das lutas por poder e pela própria sobrevivência como nação e como povo, certamente o apelo a identificação com a nação serviu também como instrumento de dominação dentro dos estados-nações, entre as classes e grupos sociais. Neste sentido, nos lembra Elias, o apelo as lealdades nacionais movida principalmente pela educação e a institucionalização das forças armadas notadamente controlada pelos Estados, "tinha ganho sólidas raízes em todas as classes e podia ser usado numa sociedade como incentivo para promover os interesses setoriais de um ou outro dos grupos dirigentes." (ELIAS, 1997, p. 141).

O nós-ideal performado pelo nacionalismo precisa estar apoiado num sistema próximo ao das crenças em deidades porque surge e cresce em 
sociedades com serviço militar massivo e obrigatório, funcionalmente diferenciadas e cujos conflitos com outras sociedades tendem a envolver toda uma nação. Em tal contexto, mecanismos de disciplina ou a obediência, o que Elias chama de coerção externa não são mais eficientes como foram no passado. A chave do nacionalismo é justamente envolver a todos os cidadãos em torno de ideais, ou melhor, crenças sociais inquestionáveis, capazes de fazer com que os indivíduos coloquem a nação acima de seu próprio bem-estar individual de maneira consciente e voluntária.

\section{Autonomia relativa, Comunicação e conhecimento}

Indivíduos isolados não formam sociedade, sociedades não existem sem indivíduos. É apenas a partir da noção de interdependência que podemos compreender essa percepção eliasiana "as sociedades não são nada além de indivíduos conectados entre si; cada indivíduo é dependente de outros, de seu (deles, dele ou dela) amor, de sua língua, de seu conhecimento, de sua identidade, da manutenção da paz e de muitas outras coisas" (ELIAS, 2006, p. 70).

A conhecida interdependência tratada por Elias provoca o entendimento de que nas figurações as relações sociais são movidas por essa relação, onde um ser humano depende do outro impreterivelmente. Até nas relações de poder mais hierarquizadas como no caso de um rei e seu vassalo, há interdependência. Ainda que as relações de poder respondam pela forma como as relações ocorrem na prática social, em um império e em qualquer outra figuração as organizações hierárquicas são inteiramente interligadas e interdependentes.

A noção de autonomia relativa, por seu turno, pretende dar conta do entendimento de outro tipo de relação. Saber que um ser humano depende de outros e que isso constitui uma relação está claro. Mas, observar essa relação interdependente do humano com a língua, não é tão comum. Podemos pensar essa relação a partir da interdependência: os seres humanos obviamente precisam da língua, mas, caso haja apenas um falante de uma determinada língua, ela não pode ser considerada como linguagem. Logo, a língua também, se assim podemos colocar, 'precisa' dos seres humanos para existir. A autonomia relativa, diz respeito, articulando a partir do mesmo exemplo, ao fato de que os falantes têm uma margem pequena de manobra em relação a língua corrente, sob pena de não ser compreendido no mundo social.

O mesmo raciocínio, nos parece, está relacionado ao que Elias chama de opinião pública em relação ao Habitus de uma nação. Neste sentido, há um frutífero diálogo entre um aspecto discutido em Teoria Simbólica e o texto publicado em português como Habitus nacional e opinião pública. ${ }^{6}$ Neste último, Elias (2006) aponta a forma como a opinião pública nos meios de comunicação em cada país atravessam suas nacionalidades. Já em Teoria Simbólica (1994) a comunicação não é tratada como opinião, mas, como o ato de comunicar através

${ }^{6}$ Originalmente dois artigos, o primeiro pulicado em 1959, o segundo em 1962. Portanto, antes da publicação de Teoria Simbólica, em 1989. 
da língua e sua função social, sendo esta, uma dimensão no tempo, desaguando, portanto, na construção ou quiçá na sociogênese da nacionalidade.

Ora, sendo a opinião pública uma das funções sociais da comunicação, e condicionante característica de determinados grupos sociais, tanto opinião pública quanto modos de comunicação, são partes de identidades nacionais.

A evolução das línguas e suas tecnologias é um condicionante do crescimento do conhecimento. Partindo do caso concreto da Inglaterra, Elias nos demonstra o fato de que a maneira como uma nação se comunica, informa sobre sua identidade nacional.

A opinião pública de um país frequentemente reage aos mesmos acontecimentos de maneira diferente da de outros países. Ela tem, em cada país, traços específicos. Na Inglaterra, obedece a regras diferentes das existentes na Alemanha ou na França. E o faz porque a história, porque sobretudo os traços básicos do desenvolvimento social das nações são, até certo grau, diferentes. Essas diferenças encontram sua sedimentação na língua e na maneira de pensar das nações. (ELIAS, 2006, p. 127).

A língua é um dos fatores que, segundo o autor, sedimenta e diferencia as nações. E isso apenas colabora para o entendimento de que apesar de todos terem uma forma de se comunicar, nossas identidades nacionais variam de acordo com o modo como nomeamos os símbolos.

A comunicação por meio de símbolos, que pode variar de sociedade para sociedade, é uma das singularidades da humanidade. [...] A imensa variabilidade de padrões sonoros, que os seres humanos podem produzir como meios de comunicação, é uma das condições da variabilidade das línguas. É também uma condição do crescimento do conhecimento. (ELIAS, 1994, p. 5).

O fato de nossa identidade nacional estar diretamente ligado a como nomeamos os símbolos nos faz perceber como o uso da língua interfere numa mesma nação, cujo acesso ao conhecimento e a terminologias simbólicas causam diferenças sociais dentro da nação.

A relação de poder através do acesso à língua nos torna capazes de "controlar os padrões de conhecimento e de fala numa sociedade, [e] é geralmente um aspecto concomitante da distribuição das oportunidades" (ELIAS, 1994, p. 8). Podemos observar como nossa visão de mundo, nossas peculiaridades enquanto indivíduos são afetadas de acordo com nosso acesso aos símbolos, e não só isso, se temos acesso e não sabemos decifrá-los, somos tão afetados quanto. Nesse sentido, a maneira como explicamos o mundo ao nosso redor, é o que auxilia no desenvolvimento, manutenção e perpetuação de grupamentos sociais.

Trata-se de como experimentamos o mundo, através de quais símbolos. Se vivemos em comunidades as quais o mundo é explicado de uma maneira 
natural e biológica, ou se vivenciamos explicações históricas e culturais, assim, replicamos de acordo com o que vivemos.

Então, Elias (1994) traz ao nosso entendimento que não há como se falar de nacionalidade sem falar dos usos e absorções dos conceitos de identidade, conhecimento, memória, linguagem e comunicação. Todos esses aspectos constituintes da nacionalidade referem-se aos âmbitos sociais e individuais, ou como quer Elias (1994b) são atributos reticulares e temporais. Logo, de acordo com Elias (1994) as características do nacionalismo dos grupos sociais podem ser alteradas a partir da evolução temporal de acesso e compartilhamento de conhecimento. Aqui, entende-se por evolução não a melhoria dos grupos, mas, as mudanças inerentes aos processos sociais.

\section{Conflitos, nação e nacionalismo}

A referida evolução temporal, se aplica da mesma maneira à predição da forma como nos relacionamos em sociedade? Uma pergunta aparentemente banal é o fundamento da construção do argumento eliasiano posto em A condição Humana, (1991) e pode nos ajudar a entender essa questão: porque os seres humanos são capazes de, em larga medida, utilizar o conhecimento científico para conhecer e eventualmente dominar os processos da natureza mas não conseguem fazer o mesmo em relação a vida social e consequentemente às relações entre as nações?

Antes de qualquer coisa, é preciso compreender como se dá a relação entre os seres humanos e os fatos naturais. A própria 'separação' entre homem e natureza já é bastante reveladora do problema, através principalmente do desenvolvimento das ciências sobre o domínio das forças da natureza e dos homens.

O que podemos perceber é que quando se trata da inter-relação humana, aparentemente não é possível controlar as relações que se estabelecem tampouco suas consequências; os limites entre a racionalidade e a irracionalidade são mais tênues do que possa parecer. Em se tratando do impacto dessa questão na construção de identidades nacionais o exemplo recorrente de Elias é o nazifascismo alemão. Compreendido com uma das formas, talvez a mais acabada, da febre hegemônica que varreu a Europa durante os séculos XIX e XX com a constituição de nações supremacistas e imperialistas ao extremo.

Fazendo jus aos processos de longa duração, Elias (1991, 1997) demonstra historicamente o processo de construção na nacionalidade alemã perpassando momentos desde a chamada Idade Média, passando pela formação do Estado alemão, o contexto da Primeira Guerra Mundial, o sentimento de humilhação com a derrota e o tratado de Versalhes; a embriaguez com a imagem da própria grandeza às vésperas da segunda grande guerra. O mito social e a febre hegemônica tornam difícil às pessoas envolvidas a análise das consequências da guerra. A estes fatores, presentes no processo identitário, 
somam-se as fantasias coletivas de que o indivíduo e a nação estão destinados à grandeza.

Esta situação ganhou mais força com a figura de Hitler, que segundo Elias (1985), vivia em um mundo semimítico. Estava presente o desejo em alcançar o poder a qualquer preço e o que legitimava esta crença era o suposto destino histórico e o suposto valor transcendente do próprio grupo. Nesta perspectiva, o fato de ser alemão já representava um grande valor, uma vez que, os alemães foram chamados a constituir "uma espécie de aristocracia da humanidade" (ELIAS, 1985, p. 49).

Desta maneira, estamos diante de um típico semióforo. Para compreendermos essa relação uma comparação com uma perspectiva diferente da eliasiana pode ser interessante. Para Chauí (2000) semióforo tem uma característica eminentemente ideológica

Um semióforo é um signo trazido à frente ou empunhado para indicar algo que significa alguma outra coisa e cujo valor não é medido por sua materialidade e sim por sua força simbólica: uma simples pedra se for o local onde um deus apareceu, ou um simples tecido de lã, se for o abrigo usado, um dia, por um herói, possuem um valor incalculável, não como pedra ou como pedaço de pano, mas como lugar sagrado ou relíquia heroica. Um semióforo é fecundo porque dele não cessam de brotar efeitos de significação. (CHAUÍ, 2000, p. 7).

Em Chauí (2000) os símbolos que caracterizam um semióforo estão ligados a uma ideologia, em Elias (1994) não há essa possibilidade, porque o símbolo está ligado a uma característica identitária e não a um chamado específico, portanto, o modo usual do símbolo em Elias é próprio da natureza humana, enquanto em Chauí pode tomar o caráter de semióforo, sendo assim uma manobra de manipulação da vida em comunidade.

No entanto, apesar de se utilizarem de formas diferentes desse termo em uma coisa eles concordam, no fato de que a evolução humana depende da utilização dos símbolos e que ambos - simbólos e semióforos - têm o poder de gerar significados. E é neste ponto que trataremos a questão. Porque para Chauí (2000) o semióforo carregado de símbolos é também um mito, como no caso de um mito fundador. "Um mito fundador é aquele que não cessa de encontrar novos meios para exprimir-se, novas linguagens, novos valores e ideias, de tal modo que, quanto mais parece ser outra coisa, tanto mais é a repetição de si mesmo" (CHAUÍ, 2000, p. 5). Ou seja, pessoas seguem os mitos a partir de crenças limitantes. Tendo este fato em tela, podemos falar, em curto e médio prazo, de uma sociedade humana pós-nacional?

\section{6. É possível uma integração para além da nação?}

Elias (2006) já havia chamado atenção que: 
[...] as sociedades se fazem nações quando a interdependência funcional entre suas regiões e seus estratos sociais, bem como entre seus níveis hierárquicos de autoridade e subordinação, tornase suficientemente grande e recíproca para que nenhum desses grupos possa desconsiderar completamente o que os outros pensam, sentem ou desejam. (ELIAS, 2006, p. 163).

Cabe considerar, entretanto a possibilidade deste argumento ser válido em se tratando de organizações pós-nacionais. Os indicadores citados por Elias estariam presentes em contextos além das nações? No que se refere a interdependência funcional entre regiões, estratos sociais e suas relações de poder, nos parece que essa é cada vez evidente entre os mais diversos pontos do planeta e não apenas nos continentes ou agrupamentos supranacionais de cunho econômico-político.

Entretanto as nações, pela forma como percebemos na argumentação que estamos dando as linhas finais, são apresentados como formações mais antigas e consolidadas do que efetivamente são. Apresentam-se como virtualmente eternas, ou ao menos imortais, dada sua historicidade. Os Estadosnação como conhecemos, já foi demonstrado aqui, surgem apenas a partir da segunda metade do século XVIII. "Nenhuma das grandes potências da Antiguidade tinha características de nação. Não havia cidadãos chineses" (ELIAS, 2006, 159).

No que se refere estritamente a possibilidade da existência e consolidação de unidades políticas pós-nacionais, é interessante notar que Elias tem duas posições distintas. Na primeira, o autor parece negar totalmente a possibilidade de uma unificação pós-nacionalista, na segunda que destacamos, o autor lança uma perspectiva aparentemente contraditória ao supor tal possibilidade de integração pós-nacional.

A perspectiva que nega o pós-nacionalismo está presente em 'A condição Humana', texto preparado, como já observamos, para celebrar os quarenta anos do fim da Segunda Guerra Mundial. Longe de pretender esquecer os fatos, um dos propósitos do autor é promover reflexões sobre a guerra, uma vez que, para superar o passado, não se pode reprimi-lo.

Elias chega a argumentar que a coação da guerra se mostra tão forte que esta parece ser o destino eterno da humanidade, mesmo com todas as suas possíveis consequências de destruição em massa, principalmente devido à utilização da tecnologia para construção de armas cada vez mais poderosas.

No caso histórico específico tratado na obra, ainda em contexto de Guerra Fria, Elias demonstra que a ameaça recíproca de uma guerra também faz parte da condição humana, pois, mesmo com o fim da Segunda Guerra Mundial a busca pela hegemonia continuou, apenas mudou a forma de conflito. A ameaça recíproca e duradoura, a hostilidade entre EUA e URSS não aconteceu somente pela ameaça militar, mas também pelos credos sociais opostos - capitalismo e comunismo. 
Neste sentido, existem dois fatores que atuam em ambos os lados: o receio de ser destruído por outro grupo e também o receio da ameaça das suas instituições sociais, que podem gerar perdas no sentido da vida de suas populações, colocando em risco sua existência social, sendo este também um aspecto da condição humana.

É principalmente imbuído da perspectiva da guerra que Elias irá argumentar que o poder de um único Estado não bastaria para instaurar a pacificação da humanidade, para estabelecer um império mundial efetivo, uma vez que, a configuração das sociedades humanas na modernidade não permitiria. As identidades, no sentido da camada-nós, de cada pessoa que formam os Estados estão muito consolidadas para que possam suportar a dominação de um único Estado.

Neste sentido, o autor afirma que esta tentativa de dominação única, à longo prazo, está condenada ao fracasso. Mesmo ocorrendo a pacificação da humanidade, no caso de um único Estado dominante, seria difícil para os demais Estados suportar a possível soberba dos hegemônicos, uma vez que "é bastante corrente que um povo, militar e economicamente mais poderoso do que os outros, desenvolva uma imagem orgulhosa de si próprio" (ELIAS, p. 94, 1985).

Elias, ao que parece, reconhece o caráter ideológico das formações nacionais, mais não vislumbra a possibilidade concreta de superação. Em outro momento, Elias, talvez pensando em um desenvolvimento social mais amplo e num futuro mais distante coloca:

[...] tenhamos em mente que a construção de nações, longe de representar o último e derradeiro surto do processo de formação de Estados, pode dar vez a uma nova integração, em um nível pósnacional mais elevado, cujo começo podemos ver, por exemplo, na Europa ocidental e na oriental, entre grupos de Estados árabes e com alguns Estados africanos. (ELIAS, 2006, p. 164).

Dois aspectos precisam ser considerados a partir dessa colocação: uma se refere ao fato de que é preciso distinguir de um lado, as ideologias nacionais que fazem uma nação parecer um sistema integrado, e coeso para todo o sempre e, de outro lado, os processos de longo prazo - analisáveis por meio da sociologia dos processos - , nos quais a integração e a desintegração, as disputas entre forças centrífugas e centrípetas e a disputa entre grupos sociais pelo poder estão presentes e são tensões típicas desse processo que está longe de ser pacífico e linear.

Além disso, devemos observar a distinção que Elias faz entre formação de Estados e nações. Estas últimas, são uma parte, um tipo bastante específico do processo de formação de Estados passíveis de análise e entendimento enquanto processos de longo prazo. Neste sentido, a integração pós-nacionalista pode vir a ser um fato, no futuro da formação de Estados.

Fica evidente, então, que não há incoerência entre as duas perspectivas apresentadas por Elias. O fato é que no primeiro caso o sociólogo está chamando 
atenção para um processo em seu desenvolvimento e trabalhando no curto e no médio prazo e ainda levando em consideração os processos ideológicos do nacionalismo (ELIAS, 1985). Na segunda referência, Elias (2006) está tratando de um processo de longo prazo, no qual os nacionalismos são vistos como uma parte do processo e não necessariamente como o fim da formação de Estados.

\section{Considerações finais}

Buscamos dialogar com Norbert Elias acerca da questão das nacionalidades tendo como pano de fundo os habitus, identidades e memória de grupamentos nacionais. Argumentamos que recentemente, particularmente desde o fim dos anos 1990, houve o crescimento de uma perspectiva pósnacionalista ancorada nos discursos políticos e econômicos do neoliberalismo e mesmo com base em intelectuais orientados com ideias cosmopolitas. Entretanto, neste primeiro quarto de século XXI temos assistido a um retorno das questões nacionalistas. Este fato nos fez recorrer a sociologia dos processos no sentido de melhor compreender tais mudanças sociais.

Observamos que os elementos constituintes da nacionalidade são vários: identidade, conhecimento, memória, linguagem e comunicação. Analisamos ainda e buscamos diferenciar os processos de evolução na formação de Estados nos quais os fatores citados acima estão necessariamente presentes, daqueles característicos das formações ideológicas, nas quais elementos de integração são construídos com o intuito de construir nacionalidades.

Claro, não esgotamos o assunto nem mesmo na obra eliasiana, dada sua amplitude e profundidade, nossa intenção foi de fato contribuir com o debate e apresentar nosso recorte teórico dentro da obra de Elias.

\section{REFERÊNCIAS}

BECK, Ulrich. The Cosmopolitan Society and its Enemies. Theory, Culture \& Society (SAGE, London, Thousand Oaks and New Delhi), v. 19, n. 1-2, p. 17$44,2002$.

BECK, Ulrich. Living in the world risk society. Economy and Society, v. 35, n. 3, p. 329-345, ago. 2006.

BECK, Ulrich. The Cosmopolitan Perspective: Sociology of the Second Age of Modernity. British Journal of Sociology, v. 51, n. 1, p. 79-106, 2000.

ELIAS, Norbert. Federico NEIBURG; WAIZBORT, Leopoldo (org.). Escritos \& ensaios: estado, processo, opinião pública. Rio de Janeiro: Jorge Zahar, 2006. v. 1.

ELIAS, Norbert. O processo civilizador: uma história dos costumes. Rio de Janeiro: Jorge Zahar, 1994a. 
ELIAS, Norbert. O processo civilizador: formação do estado e civilização. Rio de Janeiro: Jorge Zahar, 1993. v. II.

ELIAS, Nobert; DUNNING, Erich. Memória e sociedade: a busca da excitação. Lisboa: Difel, 1992.

ELIAS, Norbert. A sociedade dos indivíduos. Organizado por Michael Schöter; Tradução de Vera Ribeiro. Rio de Janeiro: Jorge Zahar, 1994b.

ELIAS, Norbert. A condição humana. Rio de Janeiro: Bertrand Brasil, 1991.

ELIAS, Norbert. Os alemães. Rio de Janeiro: Jorge Zahar, 1997.

FUKUYAMA, Francis. O fim da história e o último homem. Rio de Janeiro: Rocco, 1992.

HABERMAS, Jurgen. The Postnational Constellation. Cambridge: Polity Press, 2000.

Recebido em: 05 de março de 2021.

Aceito em: 26 de junho de 2021. Publicado em: 30 de junho de 2021. 